\title{
Energy market integration and equitable growth across countries
}

\author{
Yu Sheng ${ }^{\text {a }}$ Xunpeng Shi ${ }^{\mathrm{b}, *}$ \\ ${ }^{a}$ Crawford School of Public Policy, The Australian National University, Canberra, Australia \\ ${ }^{\mathrm{b}}$ Economic Research Institute for ASEAN and East Asia, Jakarta, Indonesia
}

\section{H I G H L I G H T S}

- EMI not only advances economic development, but also facilitates equitable growth.

- Countries with higher EMI are more likely to catch up with rich countries.

- High capital-labor ratio and literacy proportion facilitate economic convergence.

- Competitive domestic energy market helps developing countries to catch up.

\section{A R T I C L E I N F O}

\section{Article history:}

Received 3 May 2012

Received in revised form 19 October 2012

Accepted 20 October 2012

Available online 17 December 2012

\section{Keywords:}

Economic convergence

Equitable growth across countries

Energy market integration

\begin{abstract}
A B S T R A C T
Energy Market Integration (EMI) has been a goal for many regions, including the European Union and East Asia, for quite a long time. How it could play a role in facilitating equitable economic growth among a group of countries remains an empirical question that this paper will attempt to answer. The paper uses economic convergence analysis (including both the $\sigma$-convergence and $\beta$-convergence approaches) to examine the impact of EMI - measured by two newly constructed indexes (namely, the energy trade index and the energy market competition index) - at the country level on dynamic economic growth paths across countries. Its special interest lies in informing policy making related to promoting EMI. The results show that countries involved in a more integrated energy market are more likely to reduce their income disparity, suggesting that EMI may help the region to achieve equitable growth through the accelerated economic development of lagged economies.
\end{abstract}

(c) 2012 Elsevier Ltd. All rights reserved.

\section{Introduction}

Understanding the role of energy consumption in the pursuit of equitable growth across countries has emerged as a primary concern for policy makers in the past two decades. While the role of energy in promoting economic growth has been well addressed in the literature, little attention has been paid to the question of how institutional reforms in the energy sector, such as Energy Market Integration (EMI), can affect equitable growth among a group of countries. This is an important issue as it is often perceived that globalization, including economic integration, has widened the gap between rich and poor, and increased inequality [1].

\footnotetext{
Abbreviations: EAS, East Asia Summit; EMI, Energy Market Integration; EU, European Union; HCD, human capital development; NAFTA, North American Free Trade Area; PCA, Principle Component Analysis.

* Corresponding author. Address: ERIA Annex Office, Sentral Senayan II, JL. Asia Afrika No. 8, Senayan, Jakarta Pusat 10270, Indonesia. Tel.: +62 2157974460; fax: +62 2157974465 .

E-mail address: xunpeng.shi@gmail.com (X. Shi).
}

Theoretically, EMI may promote regional economic development, but there are only a few empirical studies providing supportive evidence. Recent studies on EMI [2,3] have found that the benefits from EMI have generally outweighed its costs. More generally, Park [4], followed by Lee et al. [5], Lee and Plummer [6] and Velde [7], showed that free trade agreements (including for energy products) may bring positive economic impacts to the member countries.

However, there are many limitations in the above literature. First, most of these studies used computable general equilibrium models and did not indicate positive economic effects directly obtained from EMI for the region. Secondly, EMI has always been defined as "tariff cutting" in these studies, which understates EMI's benefits through the elimination of non-tariff barriers, improvements in market accessibility and market efficiency. Thirdly, all these studies focus on the net welfare improvement provided by EMI but ignore its re-distribution effects between countries. In particular, they cannot inform policy makers about whether EMI is able to narrow development gaps across countries, and thus to facilitate equitable growth within a region. The answer to this 
question is important in encouraging the participation of developing countries in EMI. Further empirical studies are thus required to address all three limitations.

This paper examines the impact of EMI on equitable economic growth, aiming to inform policy makers of the potential role of EMI in reducing income disparity. To do so, we use economic convergence analysis to examine the impact of EMI on equitable growth across countries, using two innovative indexes to measure the level of EMI. The research provides useful information on the dynamic path of income disparity across countries resulting from EMI, in particular the impact of EMI on the ability of developing countries to reduce the level of economic inequality between themselves and developed economies (hereafter shortened to "catch-up"). The empirical results show that EMI is likely to promote the economic growth of individual countries, as well as to facilitate equitable growth within a region. This finding supports the qualitative analysis that economic integration will generally benefit all participants in terms of economic growth and income disparity reduction $[4,7,8]$. The positive impact which regional integration has on equitable growth should also give policy makers more confidence in promoting EMI.

The remainder of the paper is arranged as follows. Section II presents the methodology, model specifications and data. Section III introduces the measurement of EMI. Section IV reports the estimation results. In the last section, we present concluding remarks.

\section{Methodology, model specification and data}

As argued in the case of East Asia [9], EMI may boost economic development and reduce disparity in economic growth through three channels: transforming undeveloped comparative advantages in developing countries into real economic benefits; improving domestic energy access and use efficiency in developing countries; and encouraging the free flow of foreign direct investment to the energy sector, thus providing more energy infrastructure to developing counties.To examine changes in cross-country income disparity and EMI, we adopt a convergence analysis based on panel data regressions (the so-called 'Barro regressions'). There are two concepts of convergence employed in the analysis, namely $\sigma$-convergence and $\beta$-convergence [10]. $\sigma$-convergence indicates that the dispersion of real per capita income across countries tends to fall over time. In analyzing $\sigma$-convergence, dispersion is measured by the variance of the logarithm of per capita income across regions. Let $\sigma^{2}$ be the cross-country variance of $\ln \left(y_{i t}\right)$ at time $t$. Eq. (1) shows the definition of $\sigma^{2}$ which is equal to the sample variance of logarithmic income at $\mathrm{t}$.

$\sigma_{t}^{2}=(1 / N) \sum_{1}^{N}\left[\ln \left(y_{i t}\right)-\mu_{t}\right]^{2}$

where $\mu_{t}$ is the sample mean of logarithmic income, and the sample variance is close to the population variance when $N$ is large, which can be used for analyzing the evolution of $\sigma_{t}^{2}$. In practice, if there is a reduction in the dispersion of income levels $\left(\sigma_{t}^{2}\right)$ across economies over time, it can be argued that there is $\sigma$-convergence, and vice versa.

$\beta$-Convergence applies if a poor country or region tends to grow faster than a rich one. Under such a context, the poor country or region will 'catch up' with the rich one in terms of per capita income. This phenomenon is often described as 'regression towards the mean'.

$\ln \left(y_{i t} / y_{i, t-1}\right)=\alpha-\beta \ln \left(y_{i, t-1}\right)+u_{i t}$ where $y_{i t}$ is the real per capita income, the subscript $t$ denotes the year, and $i$ denotes the country or region. The left-hand side of the equation is the logarithm of the annual growth rate of the real per capita income. The disturbance term $\left(u_{i t}\right)$ is assumed to have a mean of zero and constant variance for all regions, and over time. $\beta$ is the convergence coefficient. It is to be noted that the intercept, $\alpha$, represents common factors across regions that can affect economic growth which are not captured elsewhere. Generally, a significantly positive $\alpha$ means higher balanced growth rates common to all countries [11]. If $\beta>0$, then Eq. (2) implies that poor regions tend to grow faster than rich ones and convergence takes place. In contrast, a zero or negative value for $\beta$ means that no convergence takes place.

Although Eq. (2) is self explainable, it is too simple to be used as our baseline model for examining economic convergence across countries, since many major determinants affecting economic growth have not been considered. To stabilize the regression function form, two factors including the capital-labor ratio $\left(K L_{i t}\right)$ and the human capital development index $\left(H C D_{i t}\right)$ have been incorporated into the $\beta$-convergence analysis to account for their potential impact. Thus, Eq. (2) can be re-written as:

$\ln \left(y_{i t} / y_{i, t-1}\right)=\alpha-\beta \ln \left(y_{i, t-1}\right)+\gamma_{1} K L_{i t}+\gamma_{2} H C D_{i t}+u_{i t}$

The capital-labor ratio $\left(K L_{i t}\right)$ is defined as the ratio of gross capital formation to total population, an indicator of the level of capital equipment (or technology) in production. The human capital development index $\left(H C D_{i t}\right)$, representing the human capital development differences across countries, is approximated by the percentage of the total population aged 15 years and older who are able to read and write (the "literacy proportion"). The control of these two factors is relevant and consistent with previous literature since both the level of technology and the development of human capital are important for promoting economic growth [12]. To capture the lag effect, we define time indicator $t$ to be every 5 years.

Finally, the dummy for the EMI index and its interaction with the countries' initial income level have been added into Eq. (3) to examine the role of EMI in affecting the economic growth convergence process. Incorporating a dummy for EMI and its interaction term with countries' initial income levels into the economic convergence analysis is justifiable. This is because the treatment is similar as to splitting our sample into low EMI and high EMI subgroups and comparing the relative convergence speed across different subgroups. Since movement towards an integrated energy market by a country can be treated as an improvement in institutional arrangements, which may have a similar role to capital accumulation and technology progress in promoting economic growth, it is expected that the speed of economic convergence would be higher in high EMI countries than in low EMI countries.

$$
\begin{aligned}
\ln \left(y_{i t} / y_{i, t-1}\right)= & \alpha-\beta \ln \left(y_{i, t-1}\right)+\gamma_{1} K L_{i t}+\gamma_{2} H C D_{i t}+\gamma_{3} D E M I_{i t} \\
& +\gamma_{4} D E M I_{i t} \times \ln \left(y_{i, t-1}\right)+u_{i t}
\end{aligned}
$$

where $D E M I_{i \mathrm{t}}$ refers to the dummy variables for EMI, which takes a value of 0 if the corresponding EMI index of country $i$ at time period $t$ is lower than its sample mean across countries and time period, and 1 otherwise. The construction of the EMI index will be discussed in the next section. It is to be noted that omitting EMI in Eq. (3) does not invalidate the ordinary least square (OLS) estimation as long as variables in both Eqs. (3) and (4) can form co-integration relationships. The co-integration is a standard requirement for time series estimation [13].

We first run the conditional $\beta$-convergence regression with Eq. (3) (excluding the EMI index) to justify the function form, and then run the $\beta$-convergence regression with Eq. (4) (including the EMI index) to assess the impact of EMI. There are in general three 
situations that may occur, each of which corresponds to a specific result. The introduction of $\gamma_{3}$ and $\gamma_{4}$ into the regression serves to decompose $\alpha$ and $\beta$ in Eq. (3), so as to provide information on the potential impact of EMI on a common economic growth trend and economic convergence across countries. First, if $\gamma_{3}$ is positive and $\gamma_{4}$ is negative and both coefficients are significant, we have evidence that EMI contributes both to higher growth within a country and to economic convergence across countries, both of which are desirable. Secondly, if $\gamma_{3}$ is negative and $\gamma_{4}$ is positive and both coefficients are significant, we have evidence that EMI contributes both to lower growth within a country and to economic divergence across countries. Thirdly, if $\gamma_{3}$ and $\gamma_{4}$ are insignificant, we have no evidence that EMI has an impact on the dynamic path.

To further explore the different roles that EMI play in affecting economic growth convergence, a similar regression procedure has also been carried out with data for different regions (or country groups) including the European Union (EU) countries ${ }^{1}$ and the North American Free Trade Area (NAFTA) countries (the USA, Canada and Mexico), and over a different time period.

As a robustness check, the EMI indexes measured as a continuous variable have also been used for all the above regressions and the results are available from the authors upon request.

Data used in this study come from four major sources, including the World Development Indicator Database [14], the cross-country historical adoption of technology (CHAT) dataset [15], the UN Comtrade Database [16] and Subramanian and Wei [17]. The dependent variable, income per capita for each country, is defined as the GDP per capita in US dollars at the constant prices (year 2000). The independent variables, including the capital-labor ratio and human capital development index, are estimated by using the data from the World Development Indicator Database and the CHAT database. In the paper, the total sample used covers 49 countries in 1960 and 118 countries in 2008, from which we have used 1017 observations in total.

\section{Measurement of energy market integration}

To measure EMI, we innovatively propose two indexes: an energy trade index and a competition index. The trade index is defined (Eq. (5)) as the weighted average of the country's imports of fossil fuel products from each trading partner, with the weights being determined by the geographical distance between the two countries (obtained from Subramanian and Wei [17]). To account for the different economy sizes, we further divide the weighted average by the domestic consumption. Bilateral trade in fossil fuel may provide useful information on EMI due to at least two factors: EMI will boost trade between the integrated markets, and bilateral trade will reflect the dependency between countries [18]. The index reflects the extent to which the country is integrated in a neighborhood EMI.

$$
\begin{aligned}
\text { EMI_TRADE }_{i t}= & \text { sum }_{j}\left(\text { energy_trade }_{i j t} / \text { distance }_{i j}\right) / n_{j} \\
& \times 1 / \text { Consum }_{i t}
\end{aligned}
$$

where EMI_TRADE $E_{i t}$ is the energy trade index, energy_trade ijt $_{t}$ is the imports of fossil fuel in country $i$ from country $j$, distance $e_{i j}$ is the distance between country $i$ and $j$ and Consum $m_{i t}$ is the total consumption of energy in country $i$. The index has been calculated for each country in each year.

\footnotetext{
${ }^{1}$ Due to data constraints, this study used 12 EU countries (that is, the UK, Germany, France, Spain, Portugal, Italy, Turkey, Ireland, Iceland, Austria, Hungary and Greece) rather than the current $27 \mathrm{EU}$ countries as a subset for the regression. Since the $12 \mathrm{EU}$ countries accounted for most of the EU production and trade, the results from this subset would not be significantly different from that with 27 EU countries.
}

The second index, the energy market competition index, is constructed by extracting information from a group of different variables using the Principle Component Analysis (PCA) approach. The PCA approach is a powerful tool for analyzing data to form a comparable index across countries when no explicit weighting is available, since the PCA approach is able to find an appropriate weight for each component [3]. Since EMI is expected to be associated with energy market liberalization and thus with competition [9], an energy market competition index may capture this domestic effect of EMI.Three variables have been employed in this paper; energy consumption productivity (Energy_prod ${ }_{i t}$, defined as GDP in millions of US dollars (in year 2000 constant prices) generated per unit of energy consumption), share of electricity consumption in total energy consumption (Electricity_share ${ }_{i t}$ ), and road sector energy use efficiency, which is defined as thousands of tonnes of energy use in the road sector for a given amount of $\mathrm{CO}_{2}$ emissions (Energy_road $\left.{ }_{i t}\right)$. We combine all these variables using the PCA approach to construct our measurement for energy market competition (Eq. (6)).

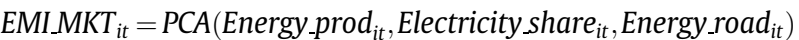

These three indicators are all expected to be positively correlated with the level of market competition. Energy productivity will increase in a more competitive market according to standard economic theory. The share of electricity consumption in total energy consumption represents the level of development, while developed countries generally have more competitive markets than less developed countries [19]. Petroleum products, primarily gasoline and diesel, are the dominant energy product used in the road sector and are usually subject to global market forces due to the globalized oil markets. Therefore, the differing efficiency of domestic consumption is likely to be determined by national factors. Fossil fuel pricing, in particular gasoline, is often regulated and is distorted in many countries. The International Energy Authority (IEA) estimated that the global total subsidies relating to oil products were US\$126 billion, $19 \%$ of the full cost of supply, and were primarily found in Non-OECD countries [20]. The more competitive the domestic energy market, the less distortions present and thus the higher the efficiency of the use of energy in the road sector (i.e. fewer $\mathrm{CO}_{2}$ emissions). In this paper we use the first (principle) component (around 50\% of the information), which, as expected, are all positive, as an index in the regression (a more detailed discussion on the PCA method can be found in Kimura and Shi [3]).

The results of the two indexes for the selected countries are reported in Table 1. The average trade index for EMI across all countries increased from 3.89 in 1960 to 5.44 in 2008, showing that the bilateral trade in energy products among neighboring countries has strengthened due to regional integration over time. Among the three regions, the average index for the East Asia Summit region (EAS) ${ }^{2}$ countries has increased from 4.33 in 1960 to 6.22 in 2008 with an annual growth rate of $0.8 \%$ a year, which is much higher than that for EU countries ( $0.6 \%$ a year) and the NAFTA countries ( $0.4 \%$ a year). This result suggests that the energy market in the EAS region has integrated more quickly than those in the $\mathrm{EU}$ and the NAFTA regions in recent years.

\footnotetext{
2 The East Asian Summit (EAS) is the regional framework governing economic integration (including EMI) in East Asia. The EAS comprises the 10 member countries of the Association of Southeast Asian Nations (ASEAN) , namely Brunei, Cambodia, Indonesia, Laos, Malaysia, Myanmar, the Philippines, Singapore, Thailand, and Vietnam, plus 6 dialog countries, i.e. Australia, China, India, Japan, the Republic of Korea and New Zealand. Although some EAS countries are not geographically located in East Asia, this region is often collectively referred to as East Asia. The US and Russia joined the EAS in later 2011 and are not included in this study.
} 
Table 1

Average energy market integration indexes: 1960-2008.

\begin{tabular}{|c|c|c|c|c|c|c|c|c|c|c|c|c|}
\hline \multirow[b]{2}{*}{ Regional block } & \multicolumn{6}{|c|}{ Energy trade index } & \multicolumn{6}{|c|}{ Competition index } \\
\hline & 1960 & 1970 & 1980 & 1990 & 2000 & 2008 & 1960 & 1970 & 1980 & 1990 & 2000 & 2008 \\
\hline EAS & 4.33 & 4.51 & 6.44 & 6.25 & 5.66 & 6.62 & 1.08 & 1.22 & 1.30 & 1.50 & 1.64 & 1.80 \\
\hline EU & 5.41 & 5.90 & 8.02 & 7.54 & 7.05 & 7.40 & 1.32 & 2.17 & 2.46 & 3.03 & 3.53 & 3.73 \\
\hline NAFTA & 4.61 & 4.79 & 6.53 & 6.14 & 5.91 & 5.49 & 2.83 & 3.88 & 4.17 & 1.73 & 1.91 & 2.09 \\
\hline All world & 3.89 & 4.19 & 5.50 & 5.50 & 4.80 & 5.44 & 1.52 & 1.71 & 1.87 & 1.96 & 1.96 & 2.34 \\
\hline
\end{tabular}

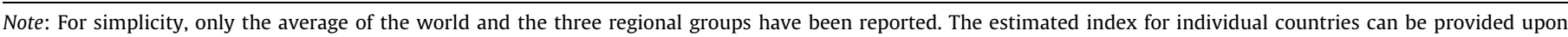
request.

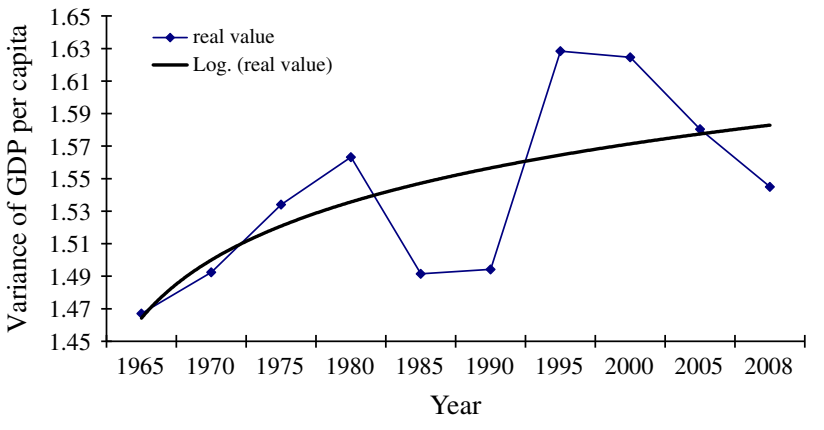

Fig. 1. Variance of real GDP across countries throughout the world: 1960-2008.

\section{Estimation results}

This section presents our empirical findings on the relationship between EMI (measured using the trade index and the energy market competition index) and economic convergence across countries.

\subsection{Economic convergence and its conditions: a baseline model}

To better understand cross-country disparity in economic development and its changing trend over time, we first use $\sigma$ convergence analysis to examine the variance of real income per capita between countries. Fig. 1 shows the logarithm of the standard deviation of GDP per capita of all the countries in our sample, over the period from 1960 to 2008. Although there were significant fluctuations, the variable has tended to increase over time. ${ }^{3} \mathrm{~A}$ further regression of the logarithmic variance of real GDP per capita on the time trend (based on Eq. (1)) showed that the estimated coefficient $(0.004)$ was positive and significant at the $1 \%$ level. ${ }^{4}$ Both the regression and the trend change analysis suggest that the disparity in real income per capita between countries has been growing over time and throughout the world over the past four decades.

Although $\sigma$-convergence analysis has shown income per capita divergence across countries, it could not indicate whether it is possible for poor countries to catch up with rich countries in terms of economic growth, nor pinpoint the factors affecting this catch up if it were possible.

To solve this problem, we use the $\beta$-convergence analysis to re-examine cross-country economic growth and its determinants. Table 2 shows the regression results based on Eqs. (2) and (3) by controlling for random (panel RE) and country-fixed effects (panel FE). In particular, Columns (1) and (2) of Table 2 show the unconditional convergence results and Columns (3) and (4) of Table 2

\footnotetext{
${ }^{3}$ Between 1960 and 2008 the log of the standard deviation of real GDP per capita across 114 countries has increased from 1.37 to 1.54 , with an annual growth rate of 0.24 per cent a year.

${ }^{4}$ The Durbin-Watson statistic is 1.44 , which is far less than 2.00 , suggesting that the regression results may not suffer from the time-series problem.
}

show the conditional convergence results when the capital-labor ratio and the HCD index have been well controlled.

Column (2) presents these results, which show that the negative relationship between changes in the logarithm of income per capita and the lagged logarithm of income per capita became more significant (with the estimated coefficient being -0.022 , significant at the $1 \%$ level). This result suggests that levels of economic growth across countries are likely to converge unconditionally, despite the significant disparity in initial income per capita level in the past (as is shown in $\sigma$-convergence test). In other words, poor countries are catching up with rich countries in terms of economic growth, reducing the income gap gradually in the long run.

Moreover, capital-labor ratio and a growing literacy proportion are both well acknowledged factors that affect the economic growth catch up and are widely used in the economic convergence analysis $[10,12]$. Following this practice, we added two controlled variables: the capital-labor ratio $(\mathrm{KL})$ and the literacy proportion (HCD) to the basic $\beta$-convergence model (Eq. (2)). The unit-root tests (i.e. the ADF test and the Philip-Pearron test) show that the residual in both models is stationary, suggesting that adding the new convergence conditions will still form the co-integration condition. The estimated coefficients of both variables are significant at 1 percent level (Column (4) of Table 2). This result, combined with the declining root-mean-squared errors (RMSE) (from 0.39 to 0.09) - the evidence of improved fitness of the new model indicate that adding the two variables into the regression has improved the model specification. In addition, the findings about capital-labor ratio and the literacy proportion are also consistent with the literature which helps to justify the use of these variables to stabilize our baseline model $[10,12]$.

\subsection{Energy market integration and growth equality}

Building on the baseline model for economic convergence, the next step is to examine the impact of EMI on the path and speed of economic convergence across countries. In doing so, we incorporates the dummies for the energy trade index and the energy market competition index, and their interaction term with the countries' initial income level into the regression (shown in Eq. (4)). Again, the unit-root tests show that the residual is stationary. The estimation results are shown in Table 3, with Columns (2) and (4) presenting the results using country fixed effects.

From Table 3, there are three findings that we wish to highlight. First, when we control for EMI, the estimated elasticities of interaction terms between the dummy for EMI and the countries' initial income are found to be negative and significant. On the one hand, when the energy trade index is used, the estimated coefficients of the interaction term between the EMI dummy and the lagged logarithm of real GDP per capita (from the panel data regression with fixed effects) is -0.003 . On the other hand, when the energy market competition index is used, the estimated coefficients of the interaction term between the EMI dummy and the lagged logarithm of real GDP per capita (from the panel data regression with fixed effects) is -0.100 . Both estimated elasticities are significant, 
Table 2

The regression results from the $\beta$-convergence analysis.

\begin{tabular}{|c|c|c|c|c|}
\hline & \multicolumn{2}{|l|}{ Model I $^{\mathrm{a}}$} & \multicolumn{2}{|l|}{ Model II $^{\mathrm{a}}$} \\
\hline & Panel (RE) & Panel (FE) & Panel (RE) & Panel (FE) \\
\hline \multicolumn{5}{|c|}{ Dependent variable: $\ln \left(y_{i t} / y_{i, t-1}\right)$} \\
\hline \multicolumn{5}{|c|}{ Lagged logged GDP (constant 2000 USD) (lncgdp2000) } \\
\hline & $-0.021^{* * *}$ & $-0.022^{* * *}$ & $-0.157^{* * *}$ & $-0.074^{* *}$ \\
\hline & $(0.008)$ & $(0.007)$ & $(0.058)$ & $(0.032)$ \\
\hline \multirow[t]{2}{*}{$K L_{i t}$} & - & - & 0.004 & $0.026^{* * *}$ \\
\hline & - & - & $(0.036)$ & $(0.009)$ \\
\hline \multirow[t]{2}{*}{$H C D_{i t}$} & - & - & $0.000^{*}$ & $0.001^{* * * *}$ \\
\hline & - & - & $(0.000)$ & $(0.000)$ \\
\hline \multirow[t]{2}{*}{ Constant } & $0.290^{* * *}$ & $0.308^{* * *}$ & $1.167^{* * * *}$ & $0.323^{* * *}$ \\
\hline & $(0.067)$ & $(0.061)$ & $(0.273)$ & $(0.070)$ \\
\hline Number of observations & 264 & 264 & 264 & 264 \\
\hline Adjusted $R$-squared & 0.005 & 0.009 & 0.108 & 0.107 \\
\hline
\end{tabular}

a Hausman test results for Models I and II are 11.47 and 12.58, which favor the fixed effect models.

*** The estimated coefficients are significant at $1 \%$ level.

** The estimated coefficients are significant at $5 \%$ level.

* The estimated coefficients are significant at $10 \%$ level.

at the $5 \%$ and the $1 \%$ levels respectively. This is strong evidence that countries with higher levels of involvement in the EMI process are more likely to achieve equitable growth. In other words, EMI, either through promoting trade facilitation or through promoting competition in the domestic energy market, may help to improve the ability of poor countries to catch up with and overtake rich countries in terms of economic growth.

Secondly, the positive coefficients for EMI dummies in both cases show that EMI has contributed to the economic growth, which adds an additional benefit of EMI to the discussion: it leads not only to higher levels of economic growth but also to a reduction in income disparity or a promotion of equitable growth across countries.

Thirdly, although EMI in general may help to reduce the economic development gap across countries, different policy instruments in relation to EMI may play different roles. When the energy trade index and the energy market competition index are separately used in the $\beta$-convergence analysis (in different regressions), the roles they play in affecting equitable growth across countries are significantly different from each other. Table 3 shows that the higher the energy trade index, the more likely is it that economic convergence and thus equitable growth can be achieved across countries, as the coefficient of the interaction term between the EMI dummy and the countries' initial income level is more negative. In the same way, the higher the energy market competition index, the more likely is it that rapid growth would take place across countries. The elasticity of the dummy for energy market competition is much larger, implying that eliminating obstacles and monopolies in domestic energy markets seems to be a more important factor in contributing to the ability of poor countries to catch up with rich countries.

\subsection{Asymmetric impact of EMI on equitable growth across regions}

How does EMI may impose a different impact on equitable growth across countries in different regions? To answer this question, we split our sample into three country groups: the EAS region, the EU region and the NAFTA region, and use a dummy variable for

Table 3

Economic convergence: 1960-2008.

\begin{tabular}{|c|c|c|c|c|}
\hline & \multicolumn{2}{|c|}{ EMI Model I $^{\mathrm{a}}$} & \multicolumn{2}{|c|}{ EMI Model II $^{\mathrm{a}}$} \\
\hline & OLS & Panel (FE) & OLS & Panel (FE) \\
\hline \multicolumn{5}{|l|}{ Dependent variable: $\ln \left(y_{i t} / y_{i, t-1}\right)$} \\
\hline $\ln \left(y_{i, t-1}\right)$ & $\begin{array}{l}-0.057^{* * *} \\
(0.019)\end{array}$ & $\begin{array}{l}-0.055^{* *} \\
(0.022)\end{array}$ & $\begin{array}{l}-0.077^{* * *} \\
(0.019)\end{array}$ & $\begin{array}{l}-0.067^{* * * *} \\
(0.021)\end{array}$ \\
\hline$K L_{i t}$ & $\begin{array}{l}0.041^{* * * *} \\
(0.015)\end{array}$ & $\begin{array}{l}0.033^{* *} \\
(0.018)\end{array}$ & $\begin{array}{l}0.054^{* * *} \\
(0.017)\end{array}$ & $\begin{array}{l}0.040^{* *} \\
(0.018)\end{array}$ \\
\hline$H C D_{i t}$ & $\begin{array}{l}0.001^{* * *} \\
(0.000)\end{array}$ & $\begin{array}{l}0.001^{* *} \\
(0.000)\end{array}$ & $\begin{array}{l}0.001^{* *} \\
(0.000)\end{array}$ & $\begin{array}{l}0.001^{* *} \\
(0.000)\end{array}$ \\
\hline$D E M I_{i t}$ (by energy trade index) & $\begin{array}{l}0.126^{* *} \\
(0.007)\end{array}$ & $\begin{array}{l}0.052^{* * *} \\
(0.008)\end{array}$ & - & - \\
\hline$D E M I_{i t} \times \ln \left(y_{i, t-1}\right)$ (by energy trade index) & $\begin{array}{l}-0.010^{* * *} \\
(0.001)\end{array}$ & $\begin{array}{l}-0.003^{* *} \\
(0.001)\end{array}$ & $\begin{array}{l}- \\
-\end{array}$ & - \\
\hline$D E M I_{i t}$ (by energy market competition index) & - & - & $\begin{array}{l}0.009^{* * *} \\
(0.001)\end{array}$ & $\begin{array}{l}0.008^{* * *} \\
(0.002)\end{array}$ \\
\hline$D E M I_{i t} \times \ln \left(y_{i, t-1}\right)$ (by energy market competition index) & - & $\begin{array}{l}- \\
-\end{array}$ & $\begin{array}{l}-0.092^{* * *} \\
(0.012)\end{array}$ & $\begin{array}{l}-0.100^{* * *} \\
(0.014)\end{array}$ \\
\hline Constant & $\begin{array}{l}0.185^{* * *} \\
(0.066)\end{array}$ & $\begin{array}{l}0.259^{* * *} \\
(0.076)\end{array}$ & $\begin{array}{l}0.316^{* * *} \\
(0.098)\end{array}$ & $\begin{array}{l}0.353^{* * * *} \\
(0.115)\end{array}$ \\
\hline Number of observations & 264 & 264 & 264 & 264 \\
\hline Adjusted $R$-squared ${ }^{\mathrm{b}}$ & 0.084 & 0.09 & 0.054 & 0.113 \\
\hline
\end{tabular}

${ }^{a}$ Hausman test results for Models I and II are 13.47 and 12.62, which favor the fixed effect model.

b The low value of adjusted $R$-squared results from the control of country fixed effects in panel data regressions.

**** The estimated coefficients are significant at $1 \%$ level.

** The estimated coefficients are significant at $5 \%$ level.

* The estimated coefficients are significant at $10 \%$ level. 
Table 4

Different impacts of EMI on equitable growth across regions: 1960-2008. ${ }^{\text {a }}$

\begin{tabular}{|c|c|c|c|}
\hline & EAS & $\mathrm{EU}$ & NAFTA \\
\hline \multicolumn{4}{|l|}{ Dependent variable: $\ln \left(y_{i t} / y_{i, t-1}\right)$} \\
\hline $\ln \left(y_{i, t-1}\right)$ & $\begin{array}{l}-0.305 \\
(0.010)\end{array}$ & $\begin{array}{l}-0.228^{* *} \\
(0.121)\end{array}$ & $\begin{array}{l}-0.201^{* *} \\
(0.089)\end{array}$ \\
\hline$K L_{i t}$ & $\begin{array}{l}0.091^{* * * *} \\
(0.025)\end{array}$ & $\begin{array}{l}0.023^{* * *} \\
(0.010)\end{array}$ & $\begin{array}{l}0.034^{* * *} \\
(0.131)\end{array}$ \\
\hline$H C D_{i t}$ & $\begin{array}{l}0.001^{* *} \\
(0.000)\end{array}$ & $\begin{array}{l}0.001^{* *} \\
(0.000)\end{array}$ & $\begin{array}{l}0.001^{* *} \\
(0.000)\end{array}$ \\
\hline$D E M I_{i t}$ (by energy trade index) & $\begin{array}{l}0.301^{\text {** }} \\
(0.120)\end{array}$ & $\begin{array}{l}1.096^{* *} \\
(0.478)\end{array}$ & $\begin{array}{l}1.011^{* * *} \\
(0.290)\end{array}$ \\
\hline$D E M I_{i t} \times \ln \left(y_{i, t-1}\right)($ by energy trade index $)$ & $\begin{array}{l}-0.036^{* *} \\
(0.015)\end{array}$ & $\begin{array}{l}-0.127^{* *} \\
(0.060)\end{array}$ & $\begin{array}{l}-0.113 \\
(0.105)\end{array}$ \\
\hline Constant & $\begin{array}{l}0.456^{\text {**** }} \\
(0.146)\end{array}$ & $\begin{array}{l}2.072^{* * *} \\
(0.401)\end{array}$ & $\begin{array}{l}2.231 \\
(2.148)\end{array}$ \\
\hline Number of observations & 57 & 79 & 27 \\
\hline Adjusted $R$-squared & 0.143 & 0.130 & 0.133 \\
\hline
\end{tabular}

a The results are based on the panel data regression with the fixed effects, as Hausman tests favor the fixed effects model. The results based on the panel data regression with the random effects are available upon request.

*** The estimated coefficients are significant at $1 \%$ level.

** The estimated coefficients are significant at $5 \%$ level.

* The estimated coefficients are significant at $10 \%$ level.

each region and its interaction term with the lagged real GDP per capita to account for region specific effects in the $\beta$-convergence analysis. Based on Eq. (4), three regressions have thus been completed for the EAS, the EU region and the NAFTA region respectively. The comparison of results obtained from the same model specification with different samples can be used to distinguish the asymmetric impact of EMI in different regions. Due to data constraints, only the energy trade index has been used for this exercise and the results are shown in Table 4 .

When the capital-labor ratio and the literacy proportion are controlled, the EAS countries have shown rapid economic growth through capital accumulation; however the low EMI countries in the EAS region are unlikely to achieve equitable growth. As shown in Column (1) of Table 4, the coefficient of lagged capital-labor ratio is positive (0.091) and significant at the $1 \%$ level, much larger than that found for the EU and NAFTA countries (0.023 and 0.034). This result suggests that the economic growth of EAS was more likely to be driven by investment than that of the rest of the world over the period from 1960 to 2008. Moreover, the coefficient of the lagged real GDP per capita for EAS countries is negative $(-0.305)$ but not significant at the $10 \%$ level. This result, compared to significantly negative coefficients of the lagged real GDP per capita for the rest of the world $(-0.228$ for the EU and -0.201 for NAFTA), suggests that incomes per capita amongst the low EMI countries of the EAS are unlikely to converge with each other.

Similarly, as in the previous section, the relative role of EMI in affecting economic growth convergence for the EAS, EU and NAFTA countries can be examined by analyzing the coefficients of the dummy variables for EMI and their interaction with the countries' initial income levels. The coefficients for the dummy of the energy trade index throughout all the regressions for the EAS, EU and NAFTA countries are all positive and significant at the 5\% level. This suggests that EMI has played an important role in promoting economic growth in all the three regions. Yet the relative impacts of EMI on equitable growth in the three regions are different. As is shown in Table 4, the elasticity of the interaction term between the dummy for the energy trade index and the lagged real GDP per capita for EAS, EU and NAFTA is -0.036 (significant at the $1 \%$ level), -0.127 (significant at the $1 \%$ level) and -0.113 (not significant at the $10 \%$ level) respectively, implying that (after accounting for regional specific effects) countries with higher EMI levels are more likely to achieve a greater reduction in the development gap among EU and EAS countries then among the NAFTA countries. In particular, economic convergence took place more quickly amongst the EU countries with high EMI levels (with the elasticity of real GDP per capita being $(-0.355=(-0.228)+(-0.127))$ than among the EAS countries $(-0.301=0+(-0.301))$ and the NAFTA countries $(-0.201=(-0.201)+0)$. A possible explanation of the relatively higher economic growth convergence among the high EMI countries in the EU could be that the more integrated market and the closer international cooperation mechanism among the EU (as well as their initial relative low income gap across countries) may have helped enlarge the positive impact of EMI in balancing regional development gaps between countries, setting a good example for the EAS countries to follow.

\section{Concluding remarks}

By using economic convergence analysis (including the $\sigma$-convergence and the $\beta$-convergence), this paper examines the impact that EMI has had on equitable growth across countries between 1960 and 2008.

The results show that countries with relatively higher levels of involvement in energy market integration are more likely to reduce their economic development gaps, which implies that EMI tends to increase the rate at which income per capita in developing countries catches up with that of their more developed neighbors. In particular, the positive impact of energy trade facilitation is more robust for the EU countries and the EAS countries than for the NAFTA countries. We also use the energy market competition index to check the robustness of these conclusions, and find consistent results.

This paper provides empirical evidence that EMI appears to advance growth equality across countries and thus brings additional benefits to member countries, in particular to developing countries. This implies that developing countries would gain more than their developed counterparts from active participation in EMI. In particular, the effect of energy market competition is much larger than that of the energy trade index, implying that improvement of domestic energy market competition could be a priority for developing countries hoping to catch up with rich countries.

\section{Acknowledgements}

This paper is one of the outcomes of the Economic Research Institute for ASEAN and East Asia (ERIA) project on Energy Market Integration in the East Asia Summit Region in FY2010. The authors are grateful to Fukunari Kimura and participants in the two project working group meetings for helpful comments and suggestions.

\section{References}

[1] Seager A. Gap between rich and poor widens. The Guardian 2007. Wednesday 20 June.

[2] Bhattacharya A, Kojima S. Economic impact analysis of East Asia energy market integration. In: Shi X, Kimura F, editors. Energy market integration in the East Asia Summit region: review of initiatives and estimation of benefits. Jakarta: Economic Research Institute for ASEAN and East Asia; 2010.

[3] Kimura F, Shi X, editors. Energy market integration in East Asia: deepening understanding and moving forward. Jakarta: Economic Research Institute for ASEAN and East Asia; 2011.

[4] Park I. Trade liberalization and long-run economic growth - a CGE model analysis of AFTA. Korea Rev Int Stud 2000;3(1):107-30.

[5] Lee H, Owen RF, Mensbrugghe Dvd. Regional integration in Asia and its effects on the EU and North America. J Asian Econ 2009;20:240-51.

[6] Lee H, Plummer MG. Estimating the Medium-term Effects of the ASEAN Economic Community. In: GTAP resources; 2010.

[7] Velde DWt. Regional integration, growth and convergence. J Econ Integr 2011;26(1):1-28.

[8] Ezaki M, Nguyen TD. Regional economic integration and its impacts on growth, income distribution and poverty in East Asia: a CGE analysis. CSID discussion paper no. 167. NAGOYA. Graduate School of International Development, Nagoya University; 2008. 
[9] Shi X, Kimura F. energy market integration in the East Asia Summit region: review of initiatives and estimation of benefits. Jakarta: Economic Research Institute for ASEAN and East Asia (ERIA); 2010.

[10] Barro RJ, Sala-i-Martin XX. Economic growth. Cambridge: MIT Press; 1995.

[11] Young AT, Higgins MJ, Levy D. Sigma convergence versus beta convergence. evidence from U.S. county-level data. J Money Credit Banking 2005;40(5):1083-93.

[12] Romer DH. Advanced macroeconomics. 2nd ed. London: McGraw-Hill; 2001.

[13] Greene W. Econometric analysis. 5th ed. New York University Press; 2002.

[14] World Bank. World development indicators 2012. Washington, (DC) The World Bank; 2012.
[15] Comin DA, Hobijn B. The CHAT dataset. National Bureau of Economic Research; 2009.

[16] United Nations commodity trade statistics datebase. <http://comtrade.un.org/ $>[08.04 .12]$.

[17] Subramanian A, Wei S-J. The WTO promotes trade, strongly but unevenly. J Int Econ 2007;72(1):151-75.

[18] Sheng Y, Shi X. Energy market integration and economic convergence. Implications for East Asia. ERIA discussion paper ERIA-DP-201105. Jakarta: Economic Research Institute for ASEAN and East Asia; 2011.

[19] Wishart I. Governing global communication. European Voice [26.04.12].

[20] IEA. World energy outlook 2011. Paris: International Energy Agency; 2011. 